\title{
Errantes no Século XXI: de Construtores a Vítimas de Trabalho Precário
}

\author{
Luís Abel Silva Filho ${ }^{1}$
}

Silvana Nunes de Queiroz $^{2}$

Resumo: A recente dinâmica econômica brasileira proporcionou bom desempenho no mercado formal de trabalho. Todos os setores de atividade econômica mostraram desempenho significativo na geração de empregos formais. Todavia, foi na construção civil que se assistiu às maiores taxas de crescimento na geração de empregos formais no Nordeste. Diante disso, este artigo tem como objetivo analisar o mercado de trabalho nesse segmento e observar a rotatividade nos postos formais de trabalho do setor. Para tanto, utilizam-se dados da Relação Anual de Informações Sociais (RAIS) e do Cadastro Geral de Empregados e Desempregados (CAGED) do Ministério do Trabalho e do Emprego (MTE). A abrangência geográfica delimita-se à região Nordeste do Brasil e o recorte temporal compreende os biênios de 2000-2001 e 2009-2010. Os principais achados confirmam a elevação dos postos de trabalho na construção civil, nas faixas mais baixas de remuneração, mesmo com a relativa melhora na escolaridade dos ocupados. Adicionalmente, registraram-se a elevadas taxas de rotatividade, mais acentuadas para a mão de obra jovem, menos escolarizada e para os postos de trabalho com rendimentos nas menores faixas de remuneração.

Palavras-chave: Mercado de Trabalho; Construção Civil; Rotatividade.

JEL: Joo, J4.

1 Professor do Departamento de Economia da Universidade Regional do Cariri - URCA. E-mail: abeleconomia@hotmail.com

2 Professora do Departamento de Economia da Universidade Regional do Cariri - URCA. E-mail: silvanaqueirozce@yahoo.com.br 


\title{
21st Century Workers: from builders to underemployment
}

\begin{abstract}
Brazil's recent economic dynamics provided good performance in the formal labor market. All sectors of economic activity showed significant performance in the generation of formal jobs. However, it was in construction that saw the highest growth rates in the generation of formal jobs in the Northeast. Therefore, this article aims to analyze the labor market in this segment and observe the turnover in formal jobs sector work. Therefore, we use data from the Annual Social Information (RAIS) and the General Register of Employed and Unemployed (CAGED) of the Ministry of Labor and Employment (MTE). The geographic range delimits to the Northeast region of Brazil and the time frame comprises the biennia of 20OO-20O1 and 2009-201O. The main findings confirm the increase in jobs in construction, in the lower pay bands, despite the relative improvement in the education of the employed. Additionally, registered to high turnover rates, higher for the hand of young work, less educated and for jobs with incomes of lower pay bands.
\end{abstract}

Keywords: Labor market; Construction; Turnover.

JEL: Joo, J4.

\section{Introdução}

A dinâmica recente da economia brasileira tem orientado novas configurações no mercado de trabalho nacional. O impulso experimentado com o avanço das obras de infraestrutura e ampliação da capacidade produtiva do país, sob as orientações do crescimento econômico da primeira década do século XXI, somando-se a ampliação do investimento governamental com o Programa de Aceleração e Crescimento (PAC), dinamizou segmentos do mercado de trabalho e promoveu o aquecimento do setor de construção civil, sobretudo, na geração de empregos formais.

Cabe, porém, destacar que o crescimento do setor de construção civil vem mostrando desempenho, desde o crescimento de oferta de crédito imobiliário no país, acoplado ao desenvolvimento de programas de habitação. É justificável assim a oferta de postos de trabalho no setor, não sendo esse um fenômeno estritamente recorrente nas regiões mais ricas do país, mas experimentado por todas elas. O Nordeste não ficou incólume ao desempenho favorável da economia brasileira e o setor da construção civil despontou de modo relevante na geração de empregos formais na região. 
Em função do contexto macroeconômico apresentado no país, as oportunidades de empregos formais foram notáveis em todos os segmentos. Contudo, a criação de vagas no setor de construção civil assegura, na sua grande maioria, oportunidade de trabalho para aquela mão de obra com menor nível de instrução e, consequentemente, a mais vulnerável aos choques negativos do mercado de trabalho. Por ser trabalho/intensivo, a construção civil permite elevada capacidade de geração de emprego para a força de trabalho menos favorecida em relação ao desempenho dos demais setores de atividades.

Adicionalmente, fenômenos como baixos salários, rotatividade e condições de trabalho precárias são experimentadas pela força de trabalho ocupada no setor. Assim, mesmo que o setor tenha criado oportunidade para a força de trabalho com menores chances de ocupação de cargos em outros setores, tais ocupações possuem baixo nível de qualidade, em sua grande maioria, e asseguram pouca possibilidade de melhoria na qualidade de vida desses trabalhadores, garantindo apenas a renda mínima proveniente do trabalho.

No Nordeste, as condições de trabalho sempre foram mais precárias que o observado no restante do país, sobretudo no centro Sul/Sudeste (Arraes et al, 2008). Assim sendo, as condições de trabalho retomam aos padrões de precarização e asseguram à força de trabalho ocupada na construção civil relativa homogeneidade entre as unidades subnacionais. Todavia, a diferença se mostra sob aspectos relacionados à diversidade regional.

Perante tal quadro, este artigo tem como objetivo analisar o mercado de trabalho na construção civil, as principais características socioeconômicas e demográficas da força de trabalho do setor, bem como a rotatividade nos postos de trabalho. Adicionalmente, consideram-se as características socioeconômicas e demográficas como condicionantes da rotatividade da força de trabalho na construção civil.

Os dados são da Relação Anual de Informações Sociais (RAIS) e do Cadastro Geral de Empregados e Desempregados (CAGED) do Ministério do Trabalho e do Emprego (MTE). A limitação do estudo deve-se ao fato de contemplar apenas os postos formais de trabalho do setor, não sendo esse motivo capaz de tirar os méritos da investigação. Os anos selecionados contemplam: 20002001 e 2009-2010, tendo como recorte geográfico o Nordeste brasileiro.

Para atingir os objetivos ora propostos, o artigo está assim estruturado: além das considerações iniciais, a segunda seção aborda algumas evidências acerca do mercado de trabalho no Nordeste; na terceira seção, serão apresentadas algumas considerações metodológicas tomadas para o estudo; na quarta seção, têm-se algumas considerações acerca do mercado de trabalho nordestino; em seguida, na quinta seção, têm-se algumas estatísticas acerca do mercado de trabalho na construção civil no Nordeste; em seguida, na sexta seção, os indicadores de rotatividade propostos pelo estudo; e, por último, algumas considerações finais. 


\section{Algumas considerações acerca do mercado de trabalho nordestino}

O desempenho econômico brasileiro da primeira década do século em curso é notável sob todos os aspectos. A ampliação da capacidade produtiva nacional; a recuperação das taxas de crescimento do Produto Interno Bruto (PIB), a partir do final de 2003; a maior participação do emprego formal em detrimento do informal, podem assegurar a melhor performance da economia do país (Cintra, 2005; Dedecca e Rosandiski, 2006; Remy, et al, 2010; Leone e Baltar, 2010). Acoplado a isto, o crescimento econômico foi resultado da melhora nos padrões de crescimento da economia mundial, com forte elevação da demanda externa (Cintra, 2005).

Destarte, a capacidade de geração de empregos no país experimentou bom desempenho, principalmente no que se refere àqueles sob regime de Consolidação das Leis do Trabalho (CLT). As taxas de desemprego aberto reduziram-se acentuadamente, na comparação com os anos de 1990, demostrando a tendência de recuperação econômica do país no início do século corrente. Sob tais aspectos, a reprodução do crescimento econômico nacional foi experimentada por todas as regiões brasileiras, em maior ou menor magnitude (Silva Filho e Queiroz, 2011).

No Nordeste, reformas estruturais basilares como a ampliação da capacidade de exportação dos portos, a dinamização da economia via atração de indústria, paralelamente a uma política fiscal favorável ao crescimento industrial da região, permitiram dinâmica acentuada na geração de postos de trabalho (Silva Filho e Queiroz, 2009; 2011). Nessa conjuntura, setores de atividade econômica com baixos registros de geração de empregos formais foram dando dimensão a novos padrões de contratação da força de trabalho.

Setores clássicos como indústria, serviços e agropecuária experimentaram favorável crescimento de suas taxas de ocupação de mão de obra. Porém, foi em segmentos como a construção civil e o comércio que os registros se mostraram mais intensos. Tal fato permitiu a contratação de uma parte da força de trabalho regional com baixa ou baixíssima capacidade de inserção em segmentos industriais e em alguns setores do terciário e ampliou as possibilidades de formalização de contratos de trabalho para a mão de obra precária da região.

Conforme se observa no gráfico 01, o setor da construção civil apresentou a maior taxa de crescimento na geração de postos de trabalho na região Nordeste, entre 2000 e 2010. O impacto desse segmento propõe a criação de postos de trabalhos para parte da PEA da região com elevado nível de inserção em outros setores de atividade. Interpretando Dedecca e Rosandiski (2006), pode-se acreditar que os "inempregáveis" de Fernando Henrique Cardoso tenham 
encontrado aqui oportunidade de inserção no mercado formal de trabalho.

Além da construção civil, o comércio também experimentou relativo desempenho durante os anos em tela. $\mathrm{O}$ aquecimento da economia na região é responsável pela dinamização do crescimento desse setor na geração de postos de trabalho. Desse modo, os efeitos das políticas de transferência de renda são visíveis, o que permite maior dinâmica no setor diante da elevação do poder de compra da população da região.

\section{GRÁFICO 01: TAXA DE CRESCIMENTO DA MÃO DE OBRA FORMAL POR SETOR DE ATIVIDADE ECONÔMICA: NORDESTE -2000-2010}

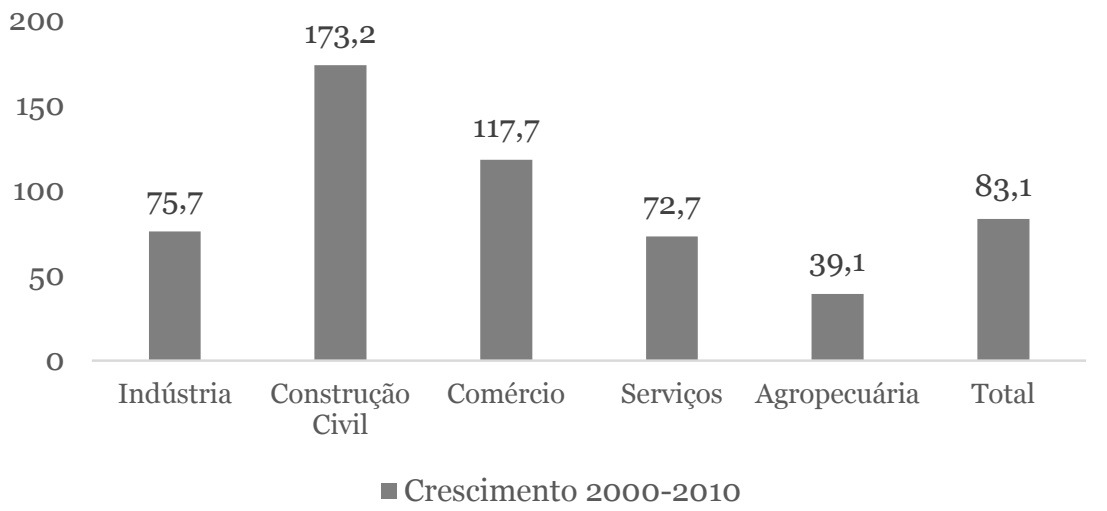

Fonte: elaborado pelos autores a partir de dados da RAIS/MTE.

Adicionalmente, faz-se pertinente destacar que a indústria obteve a terceira posição no ranking em termos de crescimento. Diante disso, os serviços e a agropecuária acusaram as menores taxas de crescimento, restando a esse último setor a menor. Nesse caso, a queda na participação das atividades monocultoras na geração de empregos, dando o avanço do processo inovador na região, pode traduzir tais resultados (Silva Filho e Mariano, 2011). Além disso, a atividade agropecuária da região tem forte relevância em segmentos da fruticultura irrigada nas regiões mais férteis e com irrigação, atuando sob processos capital/intensivo.

Mesmo assim, cabe observar que a participação relativa em cada um dos setores selecionados mantém forte concentração de ocupados naqueles de maior envergadura na geração de postos formais de trabalho, desde os anos de 1980. De acordo com o gráfico 02, o setor de serviços tem a maior participação relativa na ocupação de mão de obra formal no Nordeste em todos os anos observados. Mesmo com a leve redução desse setor, é necessário enfatizar que, no ano $2000,61,8 \%$ da força da força de trabalho formalmente ocupada na região concentrava-se nos serviços, caindo levemente para 59,3\% 
no último ano da série (2010).

O setor industrial da região oscilou entre 14,6\%, em 2003, e 15,3\%, em 2007, relativamente ao total de empregos formais no Nordeste entre os anos de 2000 e 2010. Importa frisar que, em 2010, registraram-se 14,5\% dos ocupados formalmente na região atuando no setor em destaque. Esses resultados mostram que, mesmo com elevação absoluta do segmento, o setor industrial ainda ocupa uma quantidade baixa de mão de obra formal quando comparado ao setor de serviços. Essa diferença entre a capacidade de ocupação dos serviços e da indústria é explicada por Ramos (2002) como resultado do processo de reestruturação produtiva do país ao longo dos anos de 1990.

O comércio apresenta participação relativa na ocupação de mão de obra formal no Nordeste, semelhante ao observado na indústria. A partir de 2006, a participação desse setor torna-se, embora que levemente, superior à indústria, saindo de 14,3\%, no ano 2000, para 17,08\%, em 2010. Esse segmento é bastante impulsionado pela melhora na performance regional, no que concerne à elevação da renda e é sobremaneira contemplado pela injeção de renda na economia via transferência condicionada.

GRÁFICO 2: PARTICIPAÇÃO RELATIVA DE MÃO DE OBRA FORMAL POR SETOR DE ATIVIDADE ECONÔMICA: NORDESTE -2000-2010

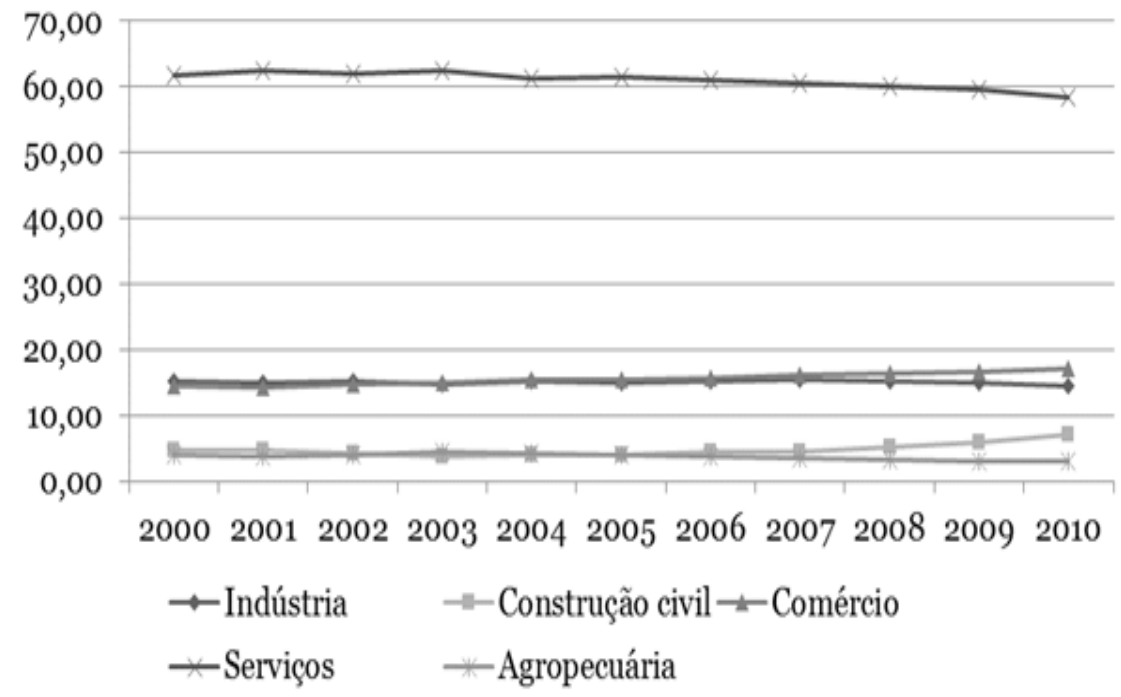

Fonte: elaborado pelos autores a partir de dados da RAIS/MTE.

A agropecuária reduz sua participação relativa quando desce de $3,8 \%$, em 2000 , para $2,9 \%$, em 2010, podendo o fenômeno ser explicado por vários fatos já observados por Silva Filho e Mariano (2011), bem como por Silva Filho et al (2012). Dentre eles, destacam-se: a redução da participação das 
atividades monocultoras na geração de postos de trabalho no setor; a inovação tecnológica nas atividades agropecuárias da região, causada pela elevação da área cultivada e pela redução da mão de obra ocupada por área de terra; e a maior participação de atividades agropecuárias com menor demanda por mão de obra, processo, aliás esse acentuadamente observado no Brasil (Balsadi, 2009).

Já a construção civil sai de uma posição semelhante à agropecuária e avança sobremaneira na ocupação de mão de obra formal no Nordeste. Esse setor, que ocupava $4,7 \%$ da força de trabalho formal atuante na região no ano 2000, registra $7,1 \%$, no ano de 2010, sendo esta a maior taxa de crescimento experimentada entre os setores de atividades econômicas selecionadas.

Deve-se ainda destacar que esse setor, assim como o agropecuário, ocupa grande quantidade de mão de obra com baixa ou nenhuma possibilidade de inserção em outros segmentos. Conforme Moreira e Targino (2005), a mão de obra ocupada na construção civil de base é, em sua grande maioria, parte da população atingida por seca na região e integrante de um forte movimento de migração pendular em busca de oportunidades, sobretudo nos grandes centros da região.

\section{Notas metodológicas}

A dinâmica do mercado de trabalho brasileiro tem sido alvo de diversas investigações científicas sob vários aspectos: a precarização de postos de trabalho (Pochmann, 1998; 1999; Dedecca, 1998; 2005), a seletividade no mercado de trabalho (Pochmann, 1999; Dedecca, 2005), a informalidade no mercado de trabalho, a rotatividade no mercado de trabalho (Cacciamali, 1992; Carvalho e Feijó, 1993; Baltar e Proni, 1995; Pazello et al, 2000; Corseuil et al, 2002 $\left.{ }^{\mathrm{a}} ; 2002 \mathrm{a}\right)$, dentre outros. Por conta disso, várias perspectivas de analises já foram constatadas em diversos setores de atividade econômica. Destarte, a contribuição acrescentada por este artigo consiste na observação do mercado de trabalho e da rotatividade no segmento formal da construção civil no Nordeste.

O método de tratamento dos dados aqui observados retoma a proposta de Corseuil et al (2002 ${ }^{\mathrm{a}}$ ) e Orellano e Pazello (2005). Ele consiste em analisar a rotatividade no mercado de trabalho considerando a contribuição por taxas de admissão, demissão e rotatividade. O que aí difere dos trabalhos anteriormente citados é o fato de se considerar a rotatividade como o movimento de entrada e de saída, e não apenas de reposição da força de trabalho.

Sob esse ângulo, definiram-se como recorte temporal os anos de 2000-2001 e 2009-2010, isto é, os biênios inicial e final da primeira década do século 
em curso. O setor de atividade selecionado foi a construção civil, não só por apresentar a maior taxa de crescimento na geração de empregos formais na região, como também incidência de trabalho precário, e maior taxa de rotatividade (Silva Filho, 2012).

Os dados são oriundos da Relação Anual de Informações Sociais (RAIS) e do Cadastro Geral de Empregados e Desempregados (CAGED) do Ministério do Trabalho e do Emprego (MTE). A limitação ao estudo advém do fato de se terem apenas informações para os postos formais de trabalho, o que não compromete a contribuição dada pela investigação em curso.

Os dados inicialmente apresentados referem-se a algumas estatísticas do mercado de trabalho na construção civil no Nordeste e, posteriormente, são construídos os indicadores de rotatividade.

Considerando-se a rotatividade como o movimento de admissão (entrada) e o movimento de demissão (saída) da força de trabalho e sua influência no estoque total de empregados na construção civil no Nordeste, a expressão seguinte determina que:

Onde:

$$
R_{i t}=\frac{\left[\sum\left(A_{i t}+D_{i t}\right)\right]}{\left[\left(L_{c i t}+L_{f i t}\right) / 2\right]}
$$

$R_{i t}=$ rotatividade no mercado de trabalho na construção civil na região em análise;

$A_{i t}=$ número de trabalhadores admitidos na construção civil no tempo em estudo;

$D_{i t}=$ número de trabalhadores desligados da construção civil no período de tempo determinado;

$L_{c i t}=$ total da força de trabalho na construção civil no início do período de tempo admitido para o estudo;

$L_{f i t}=$ total da força de trabalho na construção civil no final do período tomado para o cálculo da rotatividade.

Para se mensurar a taxa de criação e destruição de postos de trabalho, faz-se

necessário o uso da expressão que se segue: $T C=\frac{\sum_{i=1}^{n}\left(L_{a i t}-L_{d i t}\right)}{L_{i t}}(2)$, para o setor de construção civil, tal que $L_{a i t}>L_{\text {dit }}$.

A taxa de destruição de postos de trabalho no setor aqui definido assume a 
fórmula que se segue: $T D=\frac{\sum_{i=1}^{n}\left|\left(L_{d i t}-L_{a i t}\right)\right|}{L_{i t}}=\sum_{i=1}^{n}-\frac{\left(L_{a i t}-L_{d i t}\right)}{L_{i t}}$

para o setor construção civil, em que $L_{d i t}>L_{a i t}$.

Diante disso, tem-se que $\left[\left(L_{\text {ait }}-L_{d i t}\right)=\left(A_{i t}-D_{i t}\right)\right]$, o que corresponde à diferença entre o número de admitidos e o número de desligados, na construção civil, no Nordeste brasileiro, por período de tempo. Seguindo o método de análise, a taxa de criação líquida de postos de trabalho pode ser inferida da seguinte forma:

$$
T C L=\sum_{i=1}^{n} \frac{\left(\left(L_{d i t}-L_{a i t}\right)\right)}{L_{i t}}=T C-T D
$$

A partir do método exposto, obtém-se a taxa de criação (destruição) líquida de postos de trabalho, taxa de admissão, taxa de demissão e taxa de rotatividade na construção civil, levando-se em consideração a região Nordeste do Brasil e os anos determinados previamente para a investigação.

\section{Caracterização do mercado formal de trabalho no Nordeste brasileiro - 2000/2010}

A dinâmica da economia brasileira nos anos 2000 impulsionou segmentos de atividade econômica de menor projeção no cenário nacional. Na região Nordeste, as principais evidências empíricas comprovam elevação absoluta em todos os setores de atividades econômicas selecionadas (tabela 01). No entanto, não se pode deixar de observar que somente a indústria extrativa mineral, a construção civil e o comércio elevaram a participação relativa de ocupados nesses segmentos, do biênio de 2000-2001 ao de 2009-2010. Os demais setores tiveram essa participação reduzida, em alguns casos levemente.

A administração pública seguida do setor de serviços liderou, tanto no biênio 2000-2001 quanto em 2009-2010, a geração de postos formais de trabalho no Nordeste brasileiro. O primeiro setor respondia por $34,87 \%$ dos postos de trabalho e os reduziu para $31,97 \%$; já o segundo setor, reduziu de $27,24 \%$ para 26,98\% nos biênios em apreciação. As menores taxas de ocupação foram registradas na indústria extrativa mineral e nos serviços industriais de utilidade pública.

Convém destacar que, embora os setores supracitados tenham apresentado as maiores taxas de ocupação, foi na construção civil que se registrou a maior taxa 
de crescimento na geração de postos formais de trabalho na região Nordeste. Conforme os dados, esse setor ocupava $4,73 \%$ da força de trabalho formal da região no biênio 2000-2001 e elevou essa participação para 6,48\% no biênio 2009-2010. Esse resultado foi fruto de uma taxa de crescimento de 136,66\% no período, a saber: o setor, que ocupava 211.301 trabalhadores formais no primeiro biênio aumentou-os para 500.068 no segundo. Além desse setor, o comércio registrou taxa de crescimento considerável na geração de empregos formais no mesmo período (103,96\%).

TABELA 01: NÚMERO DE EMPREGO FORMAL SEGUNDO O SETOR DE ATIVIDADE ECONÔMICA: NORDESTE 2000-2001; 2009-2010

\begin{tabular}{|c|c|c|c|c|c|}
\hline \multirow{2}{*}{ Setores IBGE } & \multicolumn{2}{|c|}{ 2000-2001 } & \multicolumn{2}{|c|}{ 2009-2010 } & \multirow{2}{*}{ VAR\% } \\
\hline & $\mathrm{ABS}$ & $\%$ & ABS & $\%$ & \\
\hline Extrativa mineral & 21.072 & 0,47 & 37.552 & 0,49 & 78,21 \\
\hline $\begin{array}{l}\text { Indústria de transfor- } \\
\text { mação }\end{array}$ & 593.749 & 13,30 & 1.021 .613 & 13,24 & 72,06 \\
\hline $\begin{array}{l}\text { Serviços industriais } \\
\text { de utilidade pública }\end{array}$ & 56.794 & 1,27 & 76.638 & 0,99 & 34,94 \\
\hline Construção Civil & 211.301 & 4,73 & 500.068 & 6,48 & 136,66 \\
\hline Comércio & 637.896 & 14,29 & 1.301 .062 & 16,86 & 103,96 \\
\hline Serviços & 1.216 .139 & 27,24 & 2.081 .718 & 26,98 & 71,17 \\
\hline $\begin{array}{l}\text { Administração Pú- } \\
\text { blica }\end{array}$ & 1.556 .732 & 34,87 & 2.466 .592 & 31,97 & 58,45 \\
\hline $\begin{array}{l}\text { Agropecuária, extra- } \\
\text { ção vegetal, caça e } \\
\text { pesca }\end{array}$ & 171.175 & 3,83 & 231.272 & 3,00 & 35,11 \\
\hline$\{\tilde{n}$ classificado $\}$ & 79 & 0,00 & o & 0,00 & $-100,00$ \\
\hline Total & 4.464.935 & 100,00 & $7 \cdot 716.513$ & 100,00 & 72,82 \\
\hline
\end{tabular}

Fonte: elaborado pelos autores a partir de dados da RAIS/MTE.

Importa enfatizar que a indústria de transformação gerou menos de 600.000 postos de trabalho formais no primeiro biênio e os elevou para mais de 1.000.000 no segundo, embora tenha mantido praticamente constante sua participação relativa na geração de empregos.

No cômputo geral, a região Nordeste respondia por 4.464.935 empregos formais no biênio 2000-2001 os quais atingiram a cifra de 7.716.513 no biênio 2009-2010. Dai ter sido de 72,82\% a taxa de crescimento do primeiro para o segundo período. Esses resultados ratificam o desempenho econômico 
brasileiro dos anos 2000 e assegura à região Nordeste relativa parcela nos resultados alcançados.

Com base nesses dados, a seção que se segue procura analisar o mercado formal de trabalho no segmento de maior crescimento: construção civil. Para tanto, analisam-se as características do setor e da força de trabalho nele ocupada.

\section{Caracterização do emprego formal na construção civil no Nordeste brasileiro - 2000/2010}

Os dados da tabela 02 mostram a distribuição de trabalhadores formais na construção civil, segundo o tamanho do estabelecimento. A partir deles, vê-se que ocorreram modificações consideráveis no setor. No biênio 20002001, a distribuição de ocupados por estabelecimento registrou a maior concentração em estabelecimentos de pequeno e médio porte. Além disso, o estabelecimento de grande porte tinha a menor participação na ocupação de trabalhadores formais.

No segundo biênio (2009-2010), a dinâmica do setor apresenta mudanças em seu contexto estrutural: o estabelecimento de médio porte passa a responder pela maior cifra de ocupados; e o grande estabelecimento, embora atrás do pequeno, não deixa de apresentar significativo impulso. A própria dinâmica econômica, motivada pelas obras do Programa de Aceleração e Crescimento do Governo Federal atraiu empresas de grande porte para a região, interessadas em operar no segmento em destaque. A construção civil ganha destaque enquanto segmento ocupacional no Nordeste.

TABELA 02: NÚMERO DE EMPREGO FORMAL NA CONSTRUÇÃO CIVIL SEGUNDO A FAIXA DE REMUNERAÇÃO: NORDESTE 2000-2001; 2009-2010

\begin{tabular}{lccccc}
\hline \multirow{2}{*}{$\begin{array}{l}\text { Tamanho do estabele- } \\
\text { cimento }\end{array}$} & \multicolumn{2}{c}{ 2000-2001 } & \multicolumn{2}{c}{ 2009-2010 } & \multirow{2}{*}{ VAR \% } \\
\cline { 2 - 5 } & ABS & $\%$ & ABS & $\%$ & \\
\hline Micro & 41.560 & 19,67 & 71.477 & 14,29 & 71,99 \\
Pequeno & 73.178 & 34,63 & 137.089 & 27,41 & 87,34 \\
Médio & 68.375 & 32,36 & 170.603 & 34,12 & 149,51 \\
Grande & 28.189 & 13,34 & 120.900 & 24,18 & 328,89 \\
Total & $\mathbf{2 1 1 . 3 0 1}$ & $\mathbf{1 0 0 , 0 0}$ & $\mathbf{5 0 0 . 0 6 8}$ & $\mathbf{1 0 0 , 0 0}$ & $\mathbf{1 3 6 , 6 6}$ \\
\hline
\end{tabular}

Fonte: elaborado pelos autores a partir de dados da RAIS/MTE. 
Para ratificar a melhor performance do estabelecimento de grande porte, na condição de absorvedor de mão de obra formal, observa-se que a maior taxa de crescimento registrada foi para esse tipo de estabelecimento $(328,66 \%)$. Os estabelecimentos de micro porte registraram as menores taxas decrescimento, seguidos dos de pequeno e médio porte. Ante isso, registra-se a importância do setor de construção civil no Nordeste, em virtude da dinâmica apresentada pelos grandes estabelecimentos que, adentrando as fronteiras regionais, impulsionaram o setor como forte empregador de mão de obra formal.

Em relação ao sexo dos ocupados no setor, os dados da tabela 03 registram maioria absoluta de ocupados masculinos em todos os recortes temporais estabelecidos. No primeiro biênio, a participação de ocupados masculinos correspondia a 93,32\% das vagas ofertadas formalmente no setor. Por seu turno, as mulheres preenchiam apenas $6,68 \%$ das vagas. Esses resultados mostram que o segmento é predominantemente criador de oportunidades de trabalhos para homens. O trabalho manual, caracterizado pelo elevado esforço físico proporciona maiores oportunidades para a força de trabalho masculina (Moreira e Targino, 2005).

TABELA 03: NÚMERO DE EMPREGO FORMAL NA CONSTRUÇÃO CIVIL SEGUNDO O SEXO: NORDESTE: 2000-2001; 2009-2010

\begin{tabular}{lrrrrr}
\hline \multirow{2}{*}{ Sexo } & \multicolumn{2}{c}{$2000-2001$} & \multicolumn{2}{c}{ 2009-2010 } & \multirow{2}{*}{ VAR \% } \\
\cline { 2 - 5 } & \multicolumn{1}{c}{ ABS } & \multicolumn{1}{c}{$\%$} & \multicolumn{1}{c}{ ABS } & \multicolumn{1}{c}{$\%$} & \\
\hline Masculino & 197.178 & 93,32 & 466.358 & 93,26 & 136,52 \\
Feminino & 14.124 & 6,68 & 33.710 & 6,74 & 138,68 \\
Total & $\mathbf{2 1 1 . 3 0 1}$ & $\mathbf{1 0 0 , 0 0}$ & $\mathbf{5 0 0 . 0 6 8}$ & $\mathbf{1 0 0 , 0 0}$ & $\mathbf{1 3 6 , 6 6}$ \\
\hline
\end{tabular}

Fonte: elaborado pelos autores a partir de dados da RAIS/MTE.

No segundo biênio, destaca-se a elevada quantidade de postos de trabalho no setor. $\mathrm{O}$ crescimento conferido à construção civil na região proporcionou, em termos absolutos, a criação de 500.068 postos formais de trabalho, 93,26\% ocupados por homens, e apenas $6,74 \%$ por mulheres. Os resultados ratificam que, nesse setor, a força de trabalho masculina é predominante na ocupação de postos de trabalho. Cabe, todavia, destacar que, mesmo que a taxa de crescimento no número de empregos femininos $(138,68 \%)$ no setor tenha sido levemente superior à taxa masculina $(136,52 \%)$, as mulheres ocupam bem menos postos de trabalho que os homens nesse segmento. Não se pode concluir daqui que tenha havido modificação significativa na estrutura de funcionamento do mercado de trabalho na construção civil, no que se refere à criação de oportunidade de trabalho para as mulheres.

Na tabela 04, os dados plotados referem-se à idade dos ocupados no setor da construção civil no Nordeste brasileiro. Os principais achados revelam que 
na faixa etária de 30 a 39 anos concentra-se a maior participação absoluta e relativa, tanto no primeiro (68.348; 32,35\%) quanto no segundo (155.757; $31,15 \%$ ) biênios analisados. A menor participação observada ocorreu para a mão de obra com idade de até 17 anos, com apenas 264 ocupados no primeiro biênio e 612 no segundo.

Para as faixas etárias de 25 a 29; 50 a 64; e 65 ou mais anos, os registros mostram ter-se elevado a participação relativa de ocupados do primeiro para o último biênio. As demais faixas sofreram redução. Porém, deve-se sublinhar que em todas as faixas aqui apresentadas, elevou-se a participação absoluta de ocupados de um período para o outro.

TABELA O4: NÚMERO DE EMPREGO FORMAL NA CONSTRUÇÃO CIVIL SEGUNDO A FAIXA ETÁRIA: NORDESTE 2000-2001; 2009-2010

\begin{tabular}{lrrrrr}
\hline \multirow{2}{*}{ Idade } & \multicolumn{2}{c}{ 2000-2001 } & \multicolumn{2}{c}{ 2009-2010 } & \multirow{2}{*}{ VAR \% } \\
\cline { 2 - 5 } & \multicolumn{1}{c}{ ABS } & \multicolumn{1}{c}{$\%$} & \multicolumn{1}{c}{ ABS } & \multicolumn{1}{c}{$\%$} & \\
\hline Até 17 anos & 264 & 0,12 & 612 & 0,12 & 132,07 \\
18 a 24 & 36.323 & 17,19 & 83.715 & 16,74 & 130,48 \\
25 a 29 & 37.384 & 17,69 & 91.881 & 18,37 & 145,78 \\
30 a 39 & 68.348 & 32,35 & 155.757 & 31,15 & 127,89 \\
40 a 49 & 46.590 & 22,05 & 105.272 & 21,05 & 125,95 \\
50 a 64 & 21.576 & 10,21 & 60.659 & 12,13 & 181,14 \\
65 ou mais & 788 & 0,37 & 2.174 & 0,43 & 176,06 \\
\{n classificado $\}$ & 31 & 0,01 & 0 & 0,00 & $-100,00$ \\
Total & $\mathbf{2 1 1 . 3 0 1}$ & $\mathbf{1 0 0 , 0 0}$ & $\mathbf{5 0 0 . 0 6 8}$ & $\mathbf{1 0 0 , 0 0}$ & $\mathbf{1 3 6 , 6 6}$ \\
\hline
\end{tabular}

Fonte: elaborado pelos autores a partir de dados da RAIS/MTE.

Relativamente às taxas de crescimento, os principais achados indicam que a força de trabalho ocupada com idade entre 50 e 64 anos foi beneficiada com a expansão do setor na região. O crescimento por eles experimentado foi de 181,14\%, o maior registrado por faixa etária. Ainda, cabe observar que a mão de obra com idade de 65 ou mais anos apresentou taxa de crescimento de 176,06\%, também elevada. Por fim, menciona-se que em todas as faixas etárias se registrou crescimento superior a $100 \%$.

Em relação à escolaridade dos ocupados na construção civil no Nordeste, segundo os dados da tabela 05 houve redução relativa deles nas menores faixas de escolaridade e elevação nas maiores. No primeiro biênio, 78,37\% dos ocupados tinham escolaridade de apenas até o ensino fundamental completo. No segundo biênio, ainda se registraram 59,86\% dos ocupados nas mesmas condições. O que se tem, portanto, é a criação de vagas no segmento com baixos índices de escolaridade, mesmo diante de uma evidente melhora no 
nível de instrução dos ocupados de um período para o outro.

Infere-se, portanto, que, se reduziram os percentuais de ocupados com até o $5^{\circ}$ ano completo do ensino fundamental. As demais faixas de escolaridade estabelecidas experimentaram elevação percentual de ocupados do primeiro para o último período analisado. A maior taxa de crescimento observada foi registrada para a força de trabalho com ensino médio completo $(410,79 \%)$. Já os analfabetos atingiram variação negativa $(-8,33)$.

TABELA 05: NÚMERO DE EMPREGO FORMAL NA CONSTRUÇÃO CIVIL SEGUNDO ESCOLARIDADE: NORDESTE 2000-2001; 2009-2010

\begin{tabular}{|c|c|c|c|c|c|}
\hline \multirow{2}{*}{ Idade } & \multicolumn{2}{|c|}{ 2000-2001 } & \multicolumn{2}{|c|}{ 2009-2010 } & \multirow{2}{*}{ VAR \% } \\
\hline & $\mathrm{ABS}$ & $\%$ & ABS & $\%$ & \\
\hline Analfabeto & 9.350 & 4,42 & 8.571 & 1,71 & $-8,33$ \\
\hline Até $5^{\mathrm{a}}$ Incompleto & 57.598 & 27,26 & 71.165 & 14,23 & 23,55 \\
\hline $\begin{array}{l}5^{\text {a Completo Funda- }} \\
\text { mental }\end{array}$ & 38.375 & 18,16 & 50.060 & 10,01 & 30,45 \\
\hline $6^{\mathrm{a}}$ a $9^{\mathrm{a}}$ Fundamental & 31.873 & 15,08 & 83.722 & 16,74 & 162,67 \\
\hline $\begin{array}{l}\text { Fundamental Com- } \\
\text { pleto }\end{array}$ & 28.393 & 13,44 & 85.839 & 17,17 & 202,33 \\
\hline Médio Incompleto & 9.704 & 4,59 & 37.004 & 7,40 & 281,35 \\
\hline Médio Completo & 26.997 & 12,78 & 137.897 & 27,58 & 410,79 \\
\hline Superior Incompleto & 2.090 & 0,99 & 6.731 & 1,35 & 222,06 \\
\hline Superior Completo & 6.924 & 3,28 & 18.288 & 3,66 & 164,14 \\
\hline Mestrado & o & 0,00 & 600 & 0,12 & 0,00 \\
\hline Doutorado & $\mathrm{O}$ & 0,00 & 193 & 0,04 & 0,00 \\
\hline Total & 211.301 & 100,00 & 500.068 & 100,00 & 136,66 \\
\hline
\end{tabular}

Fonte: elaborado pelos autores a partir de dados da RAIS/MTE.

Além disso, no primeiro biênio, segundo os registros, os ocupados com ensino superior completo, constituíram apenas $3,28 \%$. No segundo, além de essa participação de ocupados com ensino superior completo se elevar para 3,66\%, destacaram-se ainda 600 ocupados com mestrado e 193 com doutorado, na construção civil no Nordeste. Apesar disso, é notória a baixa participação de ocupados no setor com melhores níveis de educação formal. Conforme os dados, esse segmento é ainda grande empregador de mão de obra com baixo nível de escolaridade, sobretudo no Nordeste.

No que se refere à média salarial dos ocupados na construção civil no Nordeste, os dados da tabela 06 mostram haver forte concentração de trabalhadores auferindo rendimentos nas primeiras faixas. A proposito, observa-se o seguinte: 
eleva-se a participação de ocupados com rendimentos nas primeiras faixas aqui estabelecidas e reduz-se elas nas melhores faixas de remuneração. No primeiro biênio, 3,08\% dos ocupados recebiam rendimentos de até 1,o salario mínimo, porém, no segundo, já havia 5,86\% desses ocupados nas mesmas condições. Enquanto isso, no biênio 2000-2001, os ocupados remunerados na faixa de mais de 1,0 e até 2,0 salários mínimos chegavam a 52,24\%. Nessas mesmas condições, eles já representavam 65,99\%, no biênio 2009-2010.

TABELA 06: NÚMERO DE EMPREGO FORMAL NA CONSTRUÇÃO CIVIL SEGUNDO FAIXA DE REMUNERAÇÃO: NORDESTE 2000-2001; 2009-2010

\begin{tabular}{lrrrrr}
\hline \multirow{2}{*}{ Idade } & \multicolumn{2}{c}{ 2000-2001 } & \multicolumn{2}{c}{ 2009-2010 } & \multirow{2}{*}{ VAR \% } \\
\cline { 2 - 5 } & \multicolumn{1}{c}{ ABS } & \multicolumn{1}{c}{$\%$} & \multicolumn{1}{c}{ ABS } & \multicolumn{1}{c}{$\%$} & \\
\hline Até 1 SM & 6.512 & 3,08 & 29.291 & 5,86 & 349,83 \\
Mais de 1 a 2 SM & 110.374 & 52,24 & 329.982 & 65,99 & 4967,67 \\
Mais de 2 a 4 SM & 68.295 & 32,32 & 94.817 & 18,96 & 1356,14 \\
Mais de 4 a 7 SM & 15.714 & 7,44 & 23.403 & 4,68 & 259,41 \\
Mais de 7 a 15 SM & 7.813 & 3,70 & 13.181 & 2,64 & 102,42 \\
Mais de 15 SM & 2.192 & 1,04 & 4.294 & 0,86 & $-34,06$ \\
\{ñn classificado\} & 403 & 0,19 & 5.103 & 1,02 & $-21,64$ \\
Total & $\mathbf{2 1 1 . 3 0 1}$ & $\mathbf{1 0 0 , 0 0}$ & $\mathbf{5 0 0 . 0 6 8}$ & $\mathbf{1 0 0 , 0 0}$ & 7579,77 \\
\hline
\end{tabular}

Fonte: elaborado pelos autores a partir de dados da RAIS/MTE.

Já nas faixas acima de 2,o salários mínimos registrou-se redução relativa de ocupados quanto rendimentos obtidos em todas elas. Na faixa de mais de 2,0 e até 4,o salários mínimos, eles respondiam por 32,32\% no primeiro biênio. Já no segundo, reduziu-se para apenas $19,96 \%$ a mão de obra ocupada no setor auferindo rendimentos nessa faixa. Nas faixas de mais de 4,0 e até 7,0; mais de 7,0 e até 15; e mais de 15 salários mínimos, houve redução relativa do primeiro para o ultimo biênio em tela (ver tabela 06).

\section{Rotatividade no mercado de trabalho formal no Nordeste}

A rotatividade no mercado de trabalho brasileiro é um fenômeno que se reproduz com elevada intensidade desde os principais estudos divulgados ainda nos anos de 1990 (Cacciamali, 1992; Carvalho e Feijó, 1993; Baltar e Proni, 1995; Pazello et al, 2000; Corseuil et al, 2002 ${ }^{\mathrm{a}}$; 2002b). Sob esse aspecto, as evidências empíricas relatam o fenômeno a partir do forte movimento de reestruturação produtiva e de desregulamentação das relações de trabalho. 
Além disso, a reestruturação das formas de produção e reprodução do sistema capitalista acentua o fenômeno em grande escala.

Diante disso, a tabela 07 apresenta as taxas de criação, destruição, rotatividade e criação (destruição) líquida de postos de trabalho no Nordeste brasileiro. As principais informações mostram as elevadas taxas de rotatividade na construção civil, na agropecuária, extração vegetal, caça e pesca. No primeiro setor citado, o movimento de entrada, assim como o de saída foi significativamente elevado. Tal dinâmica proporcionou rotatividade significativamente elevada no setor $(2,17)$. Porém, como o movimento de entrada foi pouco superior ao de saída, os registros do setor permitem observar taxa de criação líquida de postos de trabalho de apenas 0,05 , igualmente à observada para o outro setor supracitado.

A administração pública logrou a menor taxa de rotatividade, assim como a menor taxa de criação (destruição) líquida de postos de trabalhos no primeiro biênio. Já a maior taxa de criação (destruição) líquida foi registrada no setor do comércio na região $(0,07)$. Os demais setores apresentaram dinâmicas que se assemelham em alguns aspectos, porém com suas particularidades. Além disso, faz-se oportuno acrescentar que, com exceção dos serviços industriais de utilidade pública, nenhum outro setor de atividade econômica na região Nordeste do Brasil, no primeiro biênio estabelecido, apresentou taxa de criação (destruição) líquida negativa. Tal registro permite afirmar que o movimento de entrada da força de trabalho no segmento formal desse setor foi superior ao movimento de saída.

No biênio 2009-2010 as taxas de rotatividade reduziram-se em quase todos os setores de atividade econômica selecionados. Apenas os serviços industriais de utilidade pública e a agropecuária, extração vegetal, caça e pesca apresentaram taxas de rotatividade superior à observada no primeiro biênio, sendo que esse último setor apresentou a maior taxa de rotatividade no segundo biênio em questão $(1,68)$. Esse setor registrou também taxa de criação (destruição) líquida negativa $(-0,01)$, sendo que tal incidência se deu apenas nele.

A construção civil apresentou taxa de rotatividade ainda elevada $(1,64)$, ainda que inferior à observada no primeiro biênio. Porém, é oportuno destacar que esse setor apresentou a maior taxa de criação (destruição) líquida de postos de trabalho na região, no biênio 2009-2010, $(0,15)$, resultado significativamente superior ao observado pelos demais setores. O que confere à construção civil boa performance na geração de postos formais de trabalho na região. Cabe ainda acrescentar que esse setor é responsável por grande contingente de mão de obra ocupada com baixo nível de escolaridade, favorecendo a criação de novas vagas para a força de trabalho marginalmente excluída do mercado. 
TABELA 07: TAXA DE ROTATIVIDADE NO EMPREGO FORMAL SEGUNDO O SETOR DE ATIVIDADE ECONÔMICA: NORDESTE - 2000-2001 E 2009-2010

\begin{tabular}{l|c|c|c|c|c|c|c|c}
\hline & \multicolumn{5}{c|}{ 2000-2001 } & \multicolumn{5}{c}{ 2009-2010 } \\
\cline { 2 - 9 } $\begin{array}{c}\text { Setores } \\
\text { IBGE }\end{array}$ & $\begin{array}{c}\text { Taxa } \\
\text { de } \\
\text { criação }\end{array}$ & $\begin{array}{c}\text { Taxa de } \\
\text { destruição }\end{array}$ & $\begin{array}{c}\text { Taxa de } \\
\text { Rotati- } \\
\text { vidade }\end{array}$ & $\begin{array}{c}\text { Taxa } \\
\text { de } \\
\text { criação } \\
\text { liquida }\end{array}$ & $\begin{array}{c}\text { Taxa } \\
\text { de } \\
\text { criação }\end{array}$ & $\begin{array}{c}\text { Taxa de } \\
\text { destruição }\end{array}$ & $\begin{array}{c}\text { Taxa de } \\
\text { Rotati- } \\
\text { vidade }\end{array}$ & $\begin{array}{c}\text { Taxa de } \\
\text { criação } \\
\text { liquida }\end{array}$ \\
$\begin{array}{l}\text { Extrativa } \\
\text { mineral }\end{array}$ & 0,32 & 0,26 & 0,58 & 0,05 & 0,22 & 0,17 & 0,39 & 0,05 \\
$\begin{array}{l}\text { Indústria de } \\
\text { transforma- } \\
\text { ção }\end{array}$ & 0,45 & 0,40 & 0,85 & 0,04 & 0,43 & 0,38 & 0,81 & 0,05 \\
\end{tabular}

$\begin{array}{lllllllll}\text { Serviços } & 0,13 & 0,17 & 0,30 & -0,04 & 0,20 & 0,18 & 0,38 & 0,02\end{array}$ industriais

de utilidade

pública

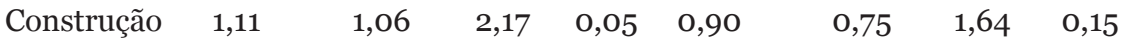

Civil

$\begin{array}{lllllllll}\text { Comércio } & 0,46 & 0,40 & 0,86 & 0,07 & 0,40 & 0,34 & 0,74 & 0,06\end{array}$

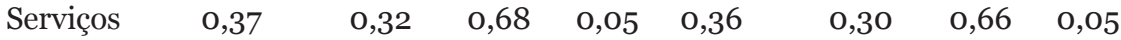

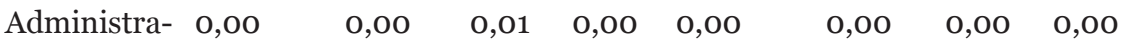
ção Pública

$\begin{array}{lllllllll}\text { Agro., } & 0,67 & 0,62 & 1,29 & 0,05 & 0,84 & 0,85 & 1,68 & -0,01\end{array}$ extração vegetal, caça e pesca

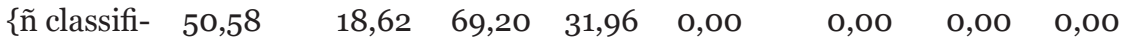
cado\}
Total
$\mathbf{0 , 3 1} \mathbf{0 , 2 8}$
$\mathbf{0 , 5 8}$
$\mathbf{0 , 0 3} \mathbf{0 , 3 1}$
$\mathbf{0 , 2 7}$
$\mathbf{0 , 5 7} \mathbf{0 , 0 4}$

Fonte: elaborado pelos autores a partir de dados da RAIS/MTE. 


\section{Condicionantes da rotatividade no mercado formal de trabalho na construção civil no Nordeste}

Alguns estudos acerca das características socioeconômicas e demográficas que afetam o mercado de trabalho já foram realizados na América Latina (Funkhouser, 1996; Marcoullier Et Al, 1997) e no Brasil (Silva Filho, 2012a) e no Nordeste (Silva Filho, 2012b). Esses achados permitiram observar que algumas características individuais de grupos populacionais no mercado de trabalho corroboram seletividade, informalidade e precarização de postos de trabalho para grupos previamente estabelecidos. Variáveis, como idade, raça/cor, sexo, além de condicionantes regionais de localização, afetam sobremaneira grupos populacionais no mercado de trabalho (Funkhouser, 1996; Marcoullier et al, 1997; Silva Filho, 2012a; Silva Filho, 2012b). Diante disso, os dados da tabela 08 mostram a rotatividade nos postos de trabalho da construção civil levando em consideração o sexo da força de trabalho admitida e desligada no período em análise. Nesse setor, a mão de obra masculina responde pelos maiores registros de rotatividade tanto no primeiro $(2,25)$ quanto no último $(1,70)$ biênio em observação. O movimento de entrada superior ao de saída conferiu a essa força de trabalho taxa de criação (destruição) líquida no setor de 0,05, em 2000-2001, e de 0,15, em 2009-2012. Por oportuno, deve-se destacar que a taxa de rotatividade do último biênio foi inferior à do primeiro.

TABELA 08: TAXA DE ROTATIVIDADE NO EMPREGO FORMAL NA CONSTRUÇÃO CIVIL SEGUNDO O SEXO: NORDESTE - 2000-2001 E 2009-2010

\begin{tabular}{|c|c|c|c|c|c|c|c|c|}
\hline \multirow[b]{2}{*}{ Sexo } & \multicolumn{4}{|c|}{ 2000-2001 } & \multicolumn{4}{|c|}{$2009-2010$} \\
\hline & $\begin{array}{l}\text { Taxa } \\
\text { de } \\
\text { cria- } \\
\text { ção }\end{array}$ & $\begin{array}{c}\text { Taxa de } \\
\text { destrui- } \\
\text { ção }\end{array}$ & $\begin{array}{l}\text { Taxa de } \\
\text { Rotati- } \\
\text { vidade }\end{array}$ & \begin{tabular}{|c|} 
Taxa \\
de \\
cria- \\
ção \\
liquida
\end{tabular} & $\begin{array}{l}\text { Taxa } \\
\text { de } \\
\text { cria- } \\
\text { ção }\end{array}$ & $\begin{array}{c}\text { Taxa de } \\
\text { destrui- } \\
\text { ção }\end{array}$ & \begin{tabular}{|l} 
Taxa de \\
Rotati- \\
vidade
\end{tabular} & $\begin{array}{c}\text { Taxa } \\
\text { de } \\
\text { cria- } \\
\text { ção } \\
\text { liquida }\end{array}$ \\
\hline Masculino & 1,15 & 1,10 & 2,25 & 0,05 & 0,92 & 0,77 & 1,70 & 0,15 \\
\hline Feminino & 0,57 & 0,47 & 1,03 & 0,10 & 0,51 & 0,39 & 0,90 & 0,13 \\
\hline$\{\tilde{n}$ class $\}$ & 0,00 & 0,00 & 0,00 & 0,00 & 0,00 & 0,00 & 0,00 & 0,00 \\
\hline Total & $\mathbf{1 , 1 1}$ & 1,06 & $\mathbf{2 , 1 7}$ & $\mathbf{0 , 0 5}$ & $\mathbf{0 , 9 0}$ & 0,75 & 1,64 & $\mathbf{0 , 1 5}$ \\
\hline
\end{tabular}

Fonte: elaborado pelos autores a partir de dados da RAIS/MTE.

Já as mulheres experimentaram rotatividade de 1,03, no biênio 2000-2001; 
e de 0,90, no biênio 2009-2010. No primeiro, a taxa de criação (destruição) líquida de postos de trabalho para elas foi superior à observada para os homens. Já no segundo, apesar da elevação $(0,13)$, foi levemente inferior ao da força de trabalho masculina. Pode-se acrescentar que a taxa de criação líquida de postos de trabalho masculina refletiu os resultados para toda a força de trabalho tanto no primeiro biênio $(0,05)$ quanto no segundo $(0,15)$.

No tocante à idade, os principais achados plotados na tabela 09 mostram elevadas taxas de rotatividade em todas as faixas etárias aqui definidas. Porém, a taxa de criação (destruição) líquida foi superior para os ocupados com idade de até 17 anos $(0,62)$ e entre 18 e $24(0,20)$. Nessas duas faixas, o movimento de entrada revelou-se bem superior ao de saída. Além disso, para as faixas etárias de 50 a 64 anos e de 65 ou mais anos, registrou-se taxa de criação (destruição) líquida negativa no primeiro biênio (2000-2001).

TABELA 09: TAXA DE ROTATIVIDADE NO EMPREGO FORMAL NA CONSTRUÇÃO CIVIL SEGUNDO A FAIXA ETÁRIA: NORDESTE - 2000-2001 E 2009-2010

\begin{tabular}{|c|c|c|c|c|c|c|c|c|}
\hline \multirow[b]{2}{*}{ Faixa etária } & \multicolumn{4}{|c|}{ 2000-2001 } & \multicolumn{4}{|c|}{ 2009-2010 } \\
\hline & $\begin{array}{c}\text { Taxa } \\
\text { de } \\
\text { criação }\end{array}$ & $\begin{array}{c}\text { Taxa de } \\
\text { destruição }\end{array}$ & $\begin{array}{l}\text { Taxa de } \\
\text { Rotati- } \\
\text { vidade }\end{array}$ & \begin{tabular}{|c|} 
Taxa \\
de \\
criação \\
liquida
\end{tabular} & \begin{tabular}{|c|} 
Taxa \\
de \\
criação
\end{tabular} & $\begin{array}{c}\text { Taxa de } \\
\text { destruição }\end{array}$ & $\begin{array}{l}\text { Taxa de } \\
\text { Rotati- } \\
\text { vidade }\end{array}$ & $\begin{array}{l}\text { Taxa de } \\
\text { criação } \\
\text { liquida }\end{array}$ \\
\hline Até 17 anos & 1,46 & 0,84 & 2,30 & 0,62 & 1,66 & 0,70 & 2,36 & 0,96 \\
\hline 18 a 24 & 1,28 & 1,08 & 2,35 & 0,20 & 1,23 & 0,92 & 2,15 & 0,32 \\
\hline 25 a 29 & 1,15 & 1,10 & 2,25 & 0,06 & 0,98 & 0,82 & 1,81 & 0,16 \\
\hline 30 a 39 & 1,10 & 1,07 & 2,17 & 0,03 & 0,87 & 0,75 & 1,62 & 0,12 \\
\hline 40 a 49 & 1,03 & 1,03 & 2,06 & 0,00 & 0,76 & 0,67 & 1,43 & 0,10 \\
\hline 50 a 64 & 0,95 & 0,99 & 1,94 & $-0,03$ & 0,61 & 0,55 & 1,16 & 0,06 \\
\hline 65 ou mais & 0,52 & 0,73 & 1,25 & $-0,20$ & 0,37 & 0,48 & 0,85 & $-0,11$ \\
\hline$\{\tilde{n}$ class $\}$ & 19,49 & 19,10 & 38,59 & 0,39 & 0,00 & 0,00 & 0,00 & 0,00 \\
\hline Total & $\mathbf{1 , 1 1}$ & 1,06 & $\mathbf{2 , 1 7}$ & $\mathbf{0 , 0 5}$ & $\mathbf{0 , 9 0}$ & $\mathbf{0 , 7 5}$ & 1,64 & $\mathbf{0 , 1 5}$ \\
\hline
\end{tabular}

Fonte: elaborado pelos autores a partir de dados da RAIS/MTE. 
No segundo biênio (2009-2010), a taxa de rotatividade eleva-se apenas para a força de trabalho com idade de até 17 anos, quando comparado o primeiro ao segundo período analisado. Todas as demais faixas apresentaram redução, embora a mão de obra com idade entre 18 e 24 anos tenha registrado ainda taxa significativamente elevada. Além do mais, as maiores taxas de criação (destruição) líquida foram registradas pela força de trabalho com idade de até 17 anos $(0,96)$ e entre 18 e 24 anos $(0,32)$. Nesse último biênio, somente a mão de obra com idade de 65 ou mais anos ocupada na construção civil no Nordeste experimentou taxa de criação (destruição) líquida negativa $(-0,11)$, por sinal elevada.

Em relação à rotatividade no setor da construção civil, segundo a escolaridade da força de trabalho ocupada, os dados da tabela 10 mostram elevadas taxas para a mão de obra com baixa escolaridade. Mas a taxa de criação líquida foi negativa apenas para a mão de obra declarada analfabeta $(-0,07)$. Também os ocupados no setor com escolaridade de até o $5^{\circ}$ ano incompleto do ensino fundamental obtiveram taxas de criação e destruição aproximadas, o que lhes conferiu baixa taxa de criação líquida. De fato, as melhores taxas de criação líquida foram registradas para a força de trabalho ocupada no setor, com escolaridade entre o ensino médio incompleto $(012)$ e completo $(0,10)$. Nessas condições, o movimento de entrada superior ao de saída conferiu-lhes taxas consideráveis (biênio, 2000-2001).

Já no segundo biênio, os dados indicam redução acentuada nas taxas de rotatividade para todas as faixas de escolaridade definidas, com exceção da força de trabalho com ensino médio completo. Além disso, em nenhuma das faixas de escolaridade estabelecidas, verificou-se criação líquida negativa. Porém, o movimento de entrada de doutores e mestres fez crescer as taxas de criação líquida para eles no último biênio em tela. Em linhas gerais, a taxa de criação líquida observada na construção civil no último biênio foi duas vezes maior que no primeiro analisado: 0,05, 2000-2001; e 0,15, 2009-2010.

Os dados da tabela 11 tratam das taxas de criação, destruição, rotatividade e criação líquida de postos de trabalho na construção civil, segundo a faixa de remuneração média dos postos de trabalho, no Nordeste brasileiro. Na primeira faixa (até 1,0 salário mínimo), a rotatividade foi significativamente elevada, determinada tanto pelo movimento de entrada quanto pelo de saída, sendo esse último inferior ao primeiro, fato graças ao qual a taxa de criação líquida foi de 0,31 no primeiro biênio observado. No mesmo período constatou-se elevada taxa de rotatividade nos postos de trabalho do setor, com remuneração de mais de 1,o e até 2,o salários mínimos. Nessa faixa, a taxa de criação líquida foi de 0,10. Já nas demais, o movimento de saída foi superior ao de entrada, com taxa de criação líquida consequentemente negativa. 
TABELA 10: TAXA DE ROTATIVIDADE NO EMPREGO FORMAL NA CONSTRUÇÃO CIVIL SEGUNDO A ESCOLARIDADE: NORDESTE - 2000-2001 E 2009-2010

\begin{tabular}{l|c|c|c|c|c|c|c|c}
\hline \multirow{2}{*}{$\begin{array}{l}\text { Escolari- } \\
\text { dade }\end{array}$} & $\begin{array}{c}\text { Taxa } \\
\text { de } \\
\text { cria- } \\
\text { ção }\end{array}$ & $\begin{array}{c}\text { Taxa de } \\
\text { destrui- } \\
\text { ção }\end{array}$ & $\begin{array}{c}\text { Taxa } \\
\text { de } \\
\text { Rotati- } \\
\text { vidade }\end{array}$ & $\begin{array}{c}\text { Taxa } \\
\text { de } \\
\text { criação } \\
\text { liquida }\end{array}$ & $\begin{array}{c}\text { Taxa } \\
\text { de } \\
\text { criação }\end{array}$ & $\begin{array}{c}\text { Taxa de } \\
\text { destrui- } \\
\text { ção }\end{array}$ & $\begin{array}{c}\text { Taxa de } \\
\text { Rotati- } \\
\text { vidade }\end{array}$ & $\begin{array}{c}\text { Taxa } \\
\text { de } \\
\text { criação } \\
\text { liquida }\end{array}$ \\
$\begin{array}{l}\text { Analfa- } \\
\text { beto }\end{array}$ & 1,22 & 1,28 & 2,50 & $-0,07$ & 0,97 & 0,80 & 1,77 & 0,16 \\
\end{tabular}

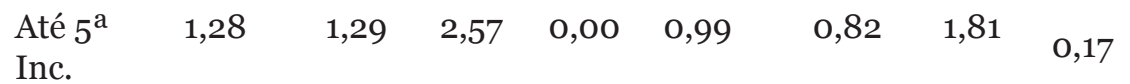

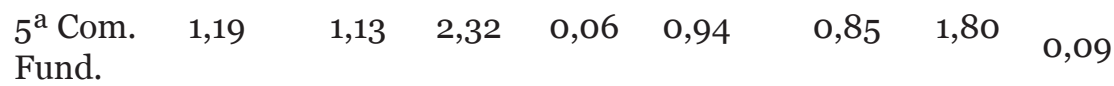

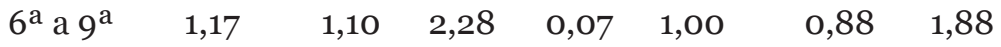

Fund.

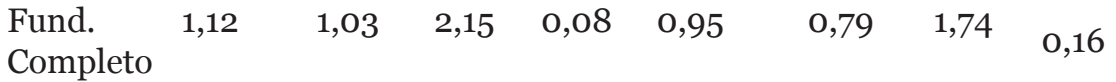

$\begin{array}{lllllllll}\text { Médio } & 0,94 & 0,82 & 1,76 & 0,12 & 0,92 & 0,74 & 1,66 & 0,18 \\ \text { Inc. } & & & & & & & & 0,18\end{array}$

Médio $\quad 0,72 \quad 0,63 \quad 1,35 \quad 0,10 \quad 0,81 \quad 0,65 \quad 1,46$

$\begin{array}{llll}\text { Completo } & 0,17\end{array}$

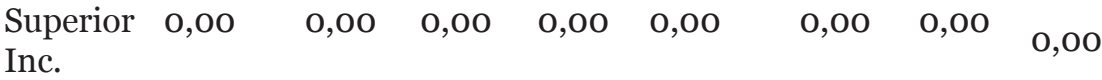

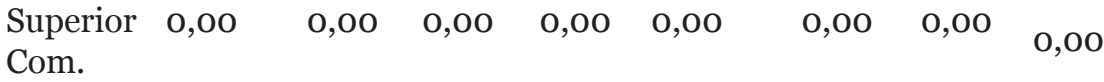

$\begin{array}{llllllll}\text { Mestrado o,oo } \quad \text { o,oo } & \text { o,oo } & \text { o,oo } & 5,88 & 4,42 & 10,30 & 1,46\end{array}$

$\begin{array}{llllllll}\text { Doutora- O,oo } \quad 0,00 & 0,00 & 0,00 & 36,65 & 26,54 & 63,18 & 10,11\end{array}$

$\begin{array}{llllllll}\text { Total } & 1,11 & 1,06 & 2,17 & 0,05 & 0,90 & 0,75 & 1,64\end{array}$

Fonte: elaborado pelos autores a partir de dados da RAIS/MTE. 
TABELA 11: TAXA DE ROTATIVIDADE NO EMPREGO FORMAL NA CONSTRUÇÃO CIVIL SEGUNDO A FAIXA DE REMUNERAÇÃO: NORDESTE - 2000-2001 E 2009-2010

\begin{tabular}{|c|c|c|c|c|c|c|c|c|}
\hline \multirow[b]{2}{*}{$\begin{array}{l}\text { Faixa de } \\
\text { Remune- } \\
\text { ração }\end{array}$} & \multicolumn{4}{|c|}{ 2000-2001 } & \multicolumn{4}{|c|}{ 2009-2010 } \\
\hline & $\begin{array}{c}\text { Taxa } \\
\text { de } \\
\text { cria- } \\
\text { ção }\end{array}$ & $\begin{array}{l}\text { Taxa de } \\
\text { destrui- } \\
\text { ção }\end{array}$ & $\begin{array}{l}\text { Taxa de } \\
\text { Rotati- } \\
\text { vidade }\end{array}$ & \begin{tabular}{|c|} 
Taxa \\
de \\
cria- \\
ção \\
liquida
\end{tabular} & $\begin{array}{c}\text { Taxa } \\
\text { de } \\
\text { cria- } \\
\text { ção }\end{array}$ & $\begin{array}{c}\text { Taxa de } \\
\text { destrui- } \\
\text { ção }\end{array}$ & $\begin{array}{l}\text { Taxa de } \\
\text { Rotati- } \\
\text { vidade }\end{array}$ & $\begin{array}{l}\text { Taxa de } \\
\text { criação } \\
\text { liquida }\end{array}$ \\
\hline Até 1 SM & 3,28 & 2,98 & 6,26 & 0,31 & 1,96 & 1,45 & 3,40 & 0,51 \\
\hline De 1-2 SM & 1,26 & 1,16 & 2,43 & 0,10 & 1,01 & 0,82 & 1,83 & , \\
\hline De 2-4 SM & 0,90 & 0,91 & 1,81 & $-0,01$ & 0,46 & 0,48 & 0,94 & 0,02 \\
\hline De 4-7 SM & 0,49 & 0,55 & 1,04 & $-0,06$ & 0,38 & 0,44 & 0,82 & $-0,00$ \\
\hline De 7-15 & 0,44 & 0,45 & 0,89 & $-0,02$ & 0,29 & 0,34 & 0,63 & $-0,06$ \\
\hline De $15 \mathrm{SM}$ & 0,43 & 0,53 & 0,97 & $-0,10$ & 0,17 & 0,21 & 0,38 & $-0,04$ \\
\hline $\begin{array}{l}\{\tilde{n} \text { classifi- } \\
\text { ca }\}\end{array}$ & 1,09 & 1,01 & 2,10 & 0,08 & 0,04 & 0,04 & 0,07 & 0,00 \\
\hline Total & 1,11 & 1,06 & 2,17 & $\mathbf{0 , 0 5}$ & $\mathbf{0 , 9 0}$ & 0,75 & 1,64 & 0,15 \\
\hline
\end{tabular}

Fonte: elaborado pelos autores a partir de dados da RAIS/MTE.

No último biênio analisado (2009-2010) as taxas de rotatividade reduziram-se em todas as faixas de remuneração. Para a força de trabalho ocupada na faixa de até 1,0 salário mínimo, elevou-se a taxa de criação líquida significativamente, haja vista que, de 0,31 no primeiro biênio ela se elevou para 0,51 no segundo. Além dessa faixa, a de mais de 1,0 e até 2,0 salário mínimo também registrou elevação de 0,10 para 0,19 . Nas demais faixas, as taxas de criação líquida mantiveram-se negativas, ratificando o forte movimento de saída superior ao de entrada.

O que se tem, portanto, é a criação de empregos formais na construção civil, no Nordeste, na faixa de remuneração de até 1,0 e entre 1,0 e 2,0 salários mínimos e destruição acentuada de vagas com remuneração nas melhores faixas. Tal fenômeno mostra os impactos da grande oferta no setor com menores salários para a força de trabalho demandante no segmento supracitado. 


\section{Considerações finais}

O objetivo deste artigo foi analisar o mercado formal de trabalho no Nordeste brasileiro com ênfase no setor da construção civil nos biênios 2000-2001 e 2009-2010. Verificaram-se então o crescimento da formalização dos ocupados no setor, bem como as características da criação e destruição de postos de trabalho. Os principais registros mostraram elevação da quantidade de ocupados formais no mercado formal de trabalho nordestino em todos os setores de atividade econômica selecionados.

Na construção civil, cerne central da investigação, assistiu-se à maior taxa de crescimento na geração de postos formais de trabalho na região. Houve também registros acentuados de trabalho para homens, mão de obra com idade entre 30 a 49 anos, com escolaridade entre o ensino médio completo e incompleto e forte concentração de ocupados auferindo rendimentos de até 2,0 salários mínimos.

No que se refere à rotatividade, o setor de construção civil apresentou a maior taxa, seguido pelo elevado movimento de entrada da mão de obra formal no setor. A taxa de criação líquida foi a maior registrada no biênio 2009-2010. Essa dinâmica foi proporcionada pela elevação da capacidade produtiva da região, bem como pela expansão das atividades econômicas regionais oriundas de investimento público em infraestrutura e de investimento privado na ampliação das unidades produtivas locais.

Quanto à rotatividade por característica demográfica da mão de obra ocupada no setor, os principais resultados mostraram elevada rotatividade para a mão de obra masculina, por ser esta, em grande maioria, constituída por operantes de base e assim de fácil substituição, bem como de rotatividade elevada em todas as faixas etárias estabelecidas, não sendo possível mensurar fenômenos que expliquem separadamente os resultados encontrados.

Já em relação aos condicionantes socioeconômicos, foi possível observar as elevadas taxas de rotatividade para a mão de obra ocupada com baixos níveis de escolaridade (até o ensino fundamental completo), sendo ainda acentuadas para o ensino médio completo e incompleto e praticamente constantes para a força de trabalho com ensino superior. Além disso, a redução nas taxas de rotatividade foi evidenciada para todas as faixas de educação formal estabelecidas no último biênio (2009-2010).

Em relação à rotatividade por faixa de remuneração dos postos de trabalho ofertados no setor, os principais achados ratificam forte movimento de entrada e saída nos postos de trabalho com remuneração média de até 2,0 salários mínimos. Além de se terem elevado as taxas de rotatividade quando comparado o primeiro ao último biênio, pode-se ainda destacar que, para os postos de trabalho que remuneravam nas faixas superiores a 2,0 salários mínimos, 
o movimento de saída foi superior ao de entrada, do que advieram taxas de criação negativas nos dois biênios em tela.

Em face do exposto, é justo destacar que, mesmo que o setor da construção civil tenha se destacado na geração de postos formais de trabalho no Nordeste, a geração de postos de trabalho ocorreu sob condições precárias, em sua grande maioria. Se, por um lado, tal criação de empregos permitiu a criação de postos de trabalho para grande parte da mão de obra com pouca ou nenhuma instrução formal e bastante afetada pela recessão econômica dos anos de 1990, por outro, permitiu a criação de postos de trabalho com elevados índices de rotatividade, baixos salários e forte incidência de precarização das relações de trabalho no segmento.

\section{Referências bibliográficas}

Arrae, A. K. de M.; Queiroz, S. N. de; Alves, C. L. B. (2008). "Mercado de trabalho formal na indústria: comparativo entre as regiões Nordeste e Sudeste nos anos de 1994 e 2004”. II Encontro Internacional Trabalho e Formação de Trabalhadores. Fortaleza, Anais ...

Balsadi, O. V. (2009). "Evolução das Ocupações e do Emprego na Agropecuária do Centro-Oeste Brasileiro no Período de 2001-05”. Informações Econômicas, SP, 39 (1), pp. 32-40.

Baltar, P. E., Proni, M. W. (1995). "Flexibilidade do trabalho, emprego e estrutura salarial no Brasil”. Campinas, SP: Unicamp, 1995 (Cadernos do CESIT e Texto para Discussão, 15).

Brasil, Ministério do Trabalho e do Empego - MTE, Relação Anual de Informações Sociais - RAIS, 2012

Brasil, Ministério do Trabalho e do Empego - MTE, Cadastro Geral de Empregados e Desempregados - CAGED, 2012

Cacciamali, M. C. (1992). "Mudanças estruturais e na regulação do mercado de trabalho no Brasil nos anos 80”. IPE/USP, Texto para Discussão Interna.

Carvalho, P. G. M., Feijó, C. A. Do V. C. (1993). "Rotatividade do pessoal ocupado na indústria: sua evolução nos anos recentes - 1985-1993”. Anais da Associação Brasileira de Estudos do Trabalho.

Cintra, M. A. M. (2005). "Suave Fracasso - a política macroeconômica brasileira entre 1999 e 2005”. Revista Novos Estudos.

Corseuil, C. H.; Ribeiro, E. P.; Santos, D. D.; Dias, R. (2002a).Criação, destruição e realocação do emprego no Brasil. Texto para discussão No 855, Rio de Janeiro, IPEA.

Corseuil, C. H.; Ribeiro, E. P.; Santos, D. D.; Dias, R. , (2002b). “Job and worker flows in Brazil”. In: Menezes-Filho, N. A. (coord.). Labor market dynamics 
in Brazil. Final Report, 2nd draft, Part I, Inter-American Development Bank Research Network, 11th round, Fipe-USP.

Dedecca, C. S. (2005). Racionalização Econômica e Trabalho no Capitalismo Avançado, ${ }^{\mathrm{a}}$ Ed., Campinas, São Paulo: Unicamp, IE.

Dedecca, C. S. (1998). "Reestruturação produtiva e tendências do emprego". In: Marco Antonio de Oliveira (org). Economia e Trabalho, cap. 10, pp. 163-185, Campinas: IE/Unicamp.

Dedecca, C. S.; Rosandiski, E. N. (2006). "Recuperação econômica e geração de empregos formais”. Revista Parcerias Estratégicas, n. 22.

Funkhouser, Edward (1996). The urban informal-sector in Central America: Household survey evidence. World Development, v. 24, $n^{o}$ 11, p. 1.737-1.751, 1996.

Leone, E. T.; Baltar, P. E. De A. (2010). "População ativa, mercado de trabalho e gênero na retomada do crescimento econômico". Encontro Nacional da Associação Brasileira de Estudos Populacionais. Anais... Caxambu: ABEP.

Marcoullier, D.; Ruiz De Castilla, V.; Woodruff, C. (1997). "Formal measures of the informal-sector wage gap in Mexico, El Salvador and Peru". Economic development and cultural change, 45 (2), pp. 367-392.

Moreira, E. Targino, I. (2005). Migração e trabalho na construção civil. IV Encontro Nacional sobre Migrações, Anais... Rio de Janeiro.

Orellano, V. I. F.; Pazello, E. T. (2005). "Evolução e determinantes da rotatividade da mão de obra nas firmas da indústria paulista na década de 1990”. Revista Pesquisa e Planejamento Econômico, 36 (1).

Pazello, E., Bivar, W., Gonzaga, G. (2000). “Criação e destruição de postos de trabalho por tamanho de empresa na indústria brasileira”. Pesquisa e Planejamento Econômico, 30 (2).

Pochmann, M. (1998). "Desemprego e políticas de emprego: tendências internacionais e o Brasil”. In: Marco Antonio de Oliveira (org). Economia e Trabalho, cap. 13, pp. 219-233, Campinas: IE/Unicamp.

Pochmann, M. (1999). O trabalho sob fogo cruzado: exclusão, desemprego e precarização no final do século, São Paulo: contexto.

Ramos, L. (2002). “A evolução da informalidade no Brasil metropolitano: 19912001”. Texto para Discussão $n^{\circ} 914$, IPEA.

Remy, M. A. P. A.; Queiroz, S. N.; Silva Filho, L. A. (2010). "Evolução Recente do Emprego Formal no Brasil - 2000-2008”. XVII Encontro Nacional da Associação Brasileira de Estudos Populacionais - ABEP. Anais... Caxambu - MG.

Silva Filho, L. A. (2012a). "Mercado de trabalho e rotatividade no emprego industrial no Nordeste”. X Encontro Nacional da Associação Brasileira de Estudos Regionais e Urbanos - ANABER. Recife, Anais...

Silva Filho, L. A. (2012b). "Rotatividade no mercado de trabalho formal brasileiro”. V Congreso de la Asociación Latinoamericana de Población, Montevideo, Uruguay, Anais...

Silva Filho, L. A.; Queiroz, S. N. De. (2009). “A trajetória da Indústria e do Emprego formal no Ceará 1996/2006”. XI Encontro Nacional de Estudos do Trabalho (ABET). Anais... Campinas. 
SILVA FILHO, QUEIROZ. Errantes no Século XXI: de Construtores a Vítimas de Trabalho Precário

Silva Filho, L. A.; Queiroz, S. N. de. (2001). "Recuperação econômica e emprego formal: avaliação empírica para o Nordeste brasileiro - 2000/2008". Revista Perspectiva Econômica, 7 (1), pp. 42-54.

Silva Filho, L. A.; Silva, J. L. M. (2011). "Evolução do emprego formal na agropecuária do Nordeste brasileiro - 1999-2009." $49^{\circ}$ Encontro Nacional da Sociedade Brasileira de Economia, Administração e Sociologia rural - SOBER. Anais... Belo Horizonte. 